\title{
Entrevista al Fiscal Gabriel De Vedia
}

Revista Derechos en Acción / ISSN 2525-1678 / e-ISSN 2525-1686

Año 4/Nº 10 Verano 2018/2019 (21 diciembre a 21 marzo), 497-502

DOl: https://doi.org/10.24215/25251678e267

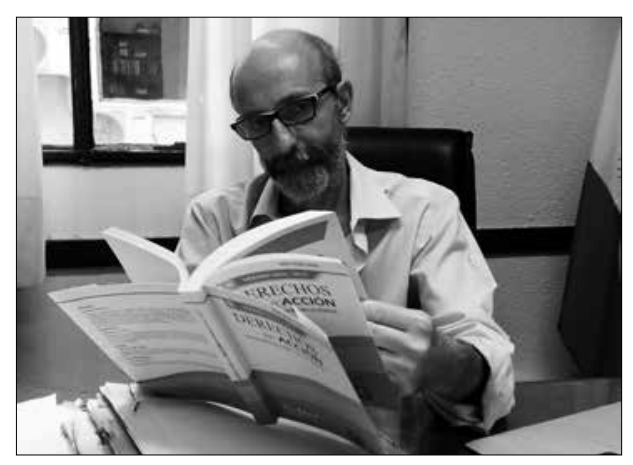

REDEA: ¿Cómo encuentra se la situación actual de la seguridad social en el país?

GDV: La situación de la Seguridad Social en un país determinado hay que entenderla desde cuestiones estructurales y cuestiones coyunturales y como cuadro intermedio, cuestiones estructurales y cuestiones coyunturales. Como estructural, la Argentina tiene un problema que no escapa al mundo entero: un diseño social desde lo liberal, visiones individualistas, triunfando el liberalismo, lo que ha llevado a diseñar a la sociedad desde lo individual y no desde lo colectivo. Y menos se diseñó con el concepto de "pueblo", elemento fundamental de la noción de Estado. Hay que trabajar para que la sociedad cambie sus esquemas mentales, la sociedad no se puede diseñarse desde lo individual sino desde lo colectivo. Pero sin embargo, hay una sinergia entre ambos que complica la situación. Si se tienen diseños individuales, las políticas de Seguridad Social se verán 
desde este prisma. Pero si hay diseños sociales, sin caer en doctrinas colectivistas, habrá otro concepto de sociedad y se entenderá que las políticas de Seguridad Social deben diseñarse desde lo colectivo y desde el concepto de pueblo.

Salvando esto cuestión estructural, podemos entender cuestiones estructurales y coyunturales. En el país es compleja la situación: porque la Seguridad Social como herramienta para distribuir el ingreso, trabajar para la justicia social, pensar en esquemas de inclusión se vuelve complicado si constantemente aumenta la insatisfacción social; si los individuos advierten ausencia del Estado en cuestiones esenciales de la sociedad. Ahí aparecen problema coyunturales que se pueden volver estructurales. ¿Cuál es un problema coyuntural hoy? Un problema coyuntural es la falta de empleo. La Seguridad Social exorbita lo laboral, lo incluye. El ser humano no es una sustancia aislada de lo que sucede en la sociedad, ni es un compartimento estanco. Se mueve en un contexto familiar, de amigos, que sufren las peripecias de la salud, de actos previsiones, de actos civiles, sociales. La Seguridad Social forma un rol esencial para tener un marco de comprensión, un marco de paliativos de esas contingencias para lograr actos civiles, comerciales y para lograr la satisfacción como persona. Para esto, es necesario la plena satisfacción de derechos humanos, civiles, sociales, comerciales. Sin estos no habrá una verdadera satisfacción de la Seguridad Social al servicio del ser humano.

Desde esta perspectiva hay que analizar los distintos sistemas de la Seguridad Social. Uno de ellos es el previsional: en él se han dado situaciones regresivas que no han sido lo progresivo que establece la Constitución Nacional ni la Convención American de Derechos Humanos ni el PIDESC. Argentina se comprometió en llevar adelante medidas progresiva ¿Cómo se mide el carácter progresivo? Se compara una norma vigente con un proyecto de ley y si esa norma ensancha derechos, o genera más derechos, es progresiva. Pero si restringe derechos y los coloca en un estado de inferioridad en reconocer derechos, es una norma regresiva e inconstitucional. La nueva norma de 
reajuste por movilidad es regresiva en este sentido. Las distintas acciones del ANSES que han hecho en estas cuestiones también. Otra es el problema de la quita de pensiones no contributivas o pensiones por discapacidad. Desde el punto de vista de la salud, hay problemas agudizados como el acceso a la salud pública. A menor empleo, menos personas tendrán obra social, prepagas y esto hace colapsar el sistema público que si encima se observa como la Ley de Presupuesto va mermando los recursos, hay menos recursos y más necesidades. Otro problema en la Seguridad Social son las viviendas: personas en situación de calle es el ejemplo de un Estado ausente. Este es el estado real de la Seguridad Social.

Y no hay que descartar aspectos vitales de una sociedad como es el estado de ánimo que se genera cuando no se satisfacen las necesidades básicas, cuando se siente que los derechos son pisoteados y cuando aumenta la preocupación por los seres queridos: ancianos, niños. La situación hace que el estado de ánimo colectivo no sea el mejor, el que se necesita para que una sociedad progrese.

REDEA: ¿Qué dificultades existen hoy en la Jurisdicción Federal de la Seguridad Social?

GDV: Se puede hablar de distintas dificultades. Una estructural y otra coyuntural de nuevo. La estructural: hay un problema de la Justicia Federal de la Seguridad Social porque hay 10 juzgados federales y 3 salas para entender todos los litigios. Si bien es cierto que la proporción litigio/jubilados no es relevante (ya que de 8 millones de jubilados, los juicios no llegan al 4\%) encima tramitan con juicios largos que pueden tardar hasta 10 años. Argentina acá no cumple tampoco las Convenciones, ni el art. 8 y 25 de la C.A .que exige un plazo razonable en los procesos y en los juicios. Un juicio no puede ser largo. De ahí que la irracionalidad deviene en un proceso cuyo trámite sería inconstitucional. Encima los juicios previsionales se rigen por el Código Procesal Civil y Comercial de la Nación. Absurdo total. Cualquier persona podría darse cuenta que un código procesal 
civil y comercial no puede regir la vida de un juicio previsional, éste fue legislado para procesos civiles y comerciales. No previsionales.. Los juicios de seguridad social que exigen mejorar los haberes jubilatorios de carácter alimentario y tuitivo el carril procesal por el que transite es el mismo que se pensó para actos comerciales y civiles. Es una maquiavélico voluntad estatal en el año 94 y 95 de hacer un esquema de juicios largos para que el Estado pague en el largo plazo. Un juicio de 2 años pasó a tardar 10 años. Esto requiere urgente modificación. La naturaleza jurídica del derecho adjetivo procesal debe revestir las mismas características del derecho de fondo: un derecho previsional que es de carácter alimentario y tuitivo requiere de un carril procesal adaptado a esas circunstancias. Debe haber adecuación entre derecho instrumental y derecho de fondo.

En perjuicio de eso, veo buena voluntad de magistrados que da la impresión de estar a la altura de las circunstancias en sus sentencias. Y espero que se puedan modificar algunas visiones que, en vez de favorecer derechos, devienen en visiones restrictivas y me imagino que se va a estar a la altura de las circunstancias.

REDEA: Diversos actores sociales los han postulado al cargo de Defensor del Pueblo de la Nación ¿Cuál es la situación de esa institución?

GDV: Diversas organizaciones sociales han postulado a mi persona como candidato a Defensor del Pueblo de la Nación. Han interpuesto presentaciones en la presentación bicameral en la Defensoría del Pueblo de la Nación. Éste trámite tiene número de expediente y trámite parlamentario. Al tener trámite parlamentario el Congreso de la Nación le debe dar un trámite favorable. Parte de estas organizaciones sociales, hay algunas que se dedican a la salud, a derechos humanos, a defensa del consumidor, del animal, víctimas de violencia, son varias. La situación de esta institución es de omisión inconstitucional: el Estado omite inconstitucionalmente. No cumple con el art. 86 de la Constitución que es la vigencia de autoridades, que es el 
Defensor de la Nación. Las Naciones Unidas advirtieron que la Argentina no cumple esto. A su vez, la Corte Suprema ha requerido al Estado que nombre el Congreso al Defensor del Pueblo. Y la Corte Suprema de la Nación también, como en fallos como Defensor del Pueblo del Chaco impugnando tarifas nacionales exorbitantes; la Corte le ha negado a la Defensoría del Pueblo del Chaco legitimación para impugnar tarifas nacionales, diciendo que sólo el Defensor del Pueblo de la Nación lo puede hacer. Pero éste no está electo, entonces la situación es grave. Por eso la situación es de una debilidad institucional y de omisión inconstitucional y de alarmante preocupación: son 10 años de inconstitucionalidad de tracto sucesivo, de ejecución continuada. Es una situación lamentable del cumplimiento de la constitución. Los llamados gobiernos de facto (entiendo que no se puede hablar de gobierno de facto sino de usurpación del poder) esos golpes de estado están cumpliendo una situación de ilegalidad continua. Bueno, lo mismo sucede con el Defensor del Pueblo que marca la constitución.

REDEA: Y, en caso de ser elegido: ¿Qué planes de gestión/ acción piensa desarrollar?

GDV: El plan busca trabajar en ejes temáticos y trabajo de territorio. Ejes temáticos pensemos en todas las contingencias sociales que existen, en todas cuestiones que se pueden violar en derechos humanos y en eso trabajará la Defensoría de la Nación. Un ejemplo: la perspectiva de género. Vamos a trabajar porque la mujer esté realmente representada en funciones importantes en la Defensoría del Pueblo. Y también pensemos todas aquellas cuestiones donde la mujer fue y es víctima y sigo siendo desplazada y vapuleada, en todas esas cuestiones trabajaremos: femicidios, desigualdad estructural en la conformación social en los cargos y funciones que se otorgan el hombre en preferencia sobre la mujer. En empleo, demostraremos por qué la mujer es más perjudicada que el hombre y queremos demostrar la radiografía de cómo la mujer fue más vìctima en las cuestiones laborales. Denunciaremos las cuestiones de trata, 
narco criminalidad, y todos los derechos que se pierden con el desempleo: acceso a la salud, situaciones emocionales, la reconstitución de la dignidad. Son todos ejes en los cuales trabajaremos. También trabajaremos en las cuestiones de protesta en las calles. Seremos una Defensoría con las puertas abiertas: no callaremos voces ni menos que menos reclamos de derechos. Entendiendo situaciones, saldremos a apoyar el reclamo de derecho de la ciudadanía y vamos a estar con ellos para que no sean más víctima de violencia institucional. Y más todavía las personas de bajos recursos o las personas de vulnerabilidad de situación estructural: mujeres, adolescentes varones y mujeres y las personas trans o todo lo que es transgénero.

Trabajaremos en la Defensa del Consumidor. Estaremos presentes en todas las denuncias con las tarifas injustas: luz, gas, agua. Trabajaremos porque haya un reconocimiento judicial y social de que todos los servicios son derechos humanos donde ningún ser humano puede ser apartado.

Son largos los ejes temáticos porque las necesidades son muchas. Defenderemos al pueblo de toda deuda social e injusta. No se puede someter la soberanía de un pueblo al establishment económico y a un conjunto de empresarios como es el FMI. 